\title{
Granulomatous slack skin: a rare subtype of mycosis fungoides*
}

\author{
Letícia Marra da Motta ${ }^{1}$ \\ Sadamitsu Nakandakari ${ }^{1}$ \\ Maria Helena Mazzi Freire Nigro ${ }^{1}$
}

\author{
Cleverson Teixeira Soares ${ }^{2}$ \\ Gardênia Viana da Silva ${ }^{1}$ \\ Leticia Stella Gardini Brandão ${ }^{1}$
}

DOI: http:/ / dx.doi.org/10.1590/abd1806-4841.20175099

\begin{abstract}
We report a case of granulomatous slack skin, a rare and indolent subtype of mycosis fungoides. It affects mainly men between the third and fourth decades. It is characterized by hardened and erithematous plaques that mainly affect flexural areas and become pedunculated after some years. Histological examination shows a dense infiltrate of small atypical lymphocytes involving the dermis (and sometimes the subcutaneous tissue) associated with histiocytic and multinucleated giant cells containing lymphocytes and elastic fibers (lymphophagocytosis and elastophagocytosis, respectively). Patients affected by this entity can develop secondary lymphomas. There are several but little effective therapeutic modalities described. Despite the indolent behavior of granulomatous slack skin, its early recognition and continuous monitoring by a dermatologist becomes essential for its management and prevention of an unfavorable outcome.
\end{abstract}

Keywords: cutaneous T-cell lymphoma; Lymphoproliferative disorders; Mycosis fungoides

\section{INTRODUCTION}

Granulomatous slack skin (GSS) is a rare and indolent subtype of mycosis fungoides (MF). ${ }^{1}$ It affects mainly adult males in the third and fourth decades of life (mean age $=37$ years) ${ }^{2}$ It is characterized by hardened erythematous plaques involving the flexural areas. With evolution, the lesions become pedunculated., ${ }^{2,3}$ Patients with this entity should be followed regularly, as they may develop secondary lymphomas, such as mycosis fungoides and Hodgkin's and non-Hodgkin's lymphomas. ${ }^{2-5}$ In well-established lesions, there is a dense infiltrate of small atypical lymphocytes with convoluted nuclei involving the dermis - and sometimes the subcutaneous tissue associated with histiocytes and multinucleated giant cells containing lymphocytes and elastic fibers in the cytoplasm (lymphophagocytosis and elastophagocytosis). Non-caseating tuberculoid granulomas can be found. Special stains show diffuse loss of elastic fibers. Neoplastic lymphocytes display a T-helper immunophenotype (CD3+, $\mathrm{CD} 4+, \mathrm{CD} 45 \mathrm{RO}+, \mathrm{CD} 5+, \mathrm{CD} 7+$, and CD30-). Multinucleated giant cells at the center of the lesions are positive for CD68, surrounded by CD1a-positive cells. ${ }^{1,4-7}$ TCR monoclonal gene rearrangement has been identified. ${ }^{8}$ The main differential diagnosis is with granulomatous mycosis fungoides (GMF), since elastophagocytosis can be found in both. However, in GMF, elastic fiber loss is focal, giant cells have fewer nuclei, and lymphophagocytosis is infrequent. ${ }^{9}$ Some types of therapy include surgical excision, topical or systemic steroids, PUVA therapy, nitrogen mustard, and chemotherapy. Despite the several therapies reported, none of them is well-defined. ${ }^{2,4,5}$

\section{CASE REPORT}

We report a 35-year-old male patient presented with itchy and growing plaques on the left leg and right thigh for six years. He was diagnosed, by another health service, with Rosai-Dorfman disease, undergoing six sessions of chemotherapy (cyclophosphamide, vincristine, and prednisone) with no improvement. Physical examination revealed hardened erythematous-violet plaques on the left leg and right thigh, tissue laxity and bilateral supraclavicular and left inguinal hyperchromia associated with left inguinal fibroelastic adenopathy (Figures 1 and 2). Complete blood count, biochemistry, chest X-ray, fine-needle aspiration of the inguinal lymph node, and bone marrow biopsy were performed without alterations. Skin biopsies showed a dense infiltrate of small and atypical lymphocytes, present from the epidermis to the subcutaneous layer. Multinucleated giant cells permeated and phagocytosed atypical lymphocytes, a process known as the phenomenon of emperipolesis (Figures 3 and 4). Verhoeff's stain showed no elastic fibers inside the neoplastic infiltrate and elastophagocytosis (Figure 5). Immunohistochemical study demonstrated expression of neoplastic $\mathrm{T}$ lymphocytes (CD3+, CD4+, CD45RO+, CD8-, CD 20-, and CD30-) and $\mathrm{CD} 68+$ and $\mathrm{CD} 1 \mathrm{a}+$ multinucleated giant cells (Figure 6). Cultures for fungi and mycobacteria from biopsy material were both negative. After coherent histological findings, we reached a diagnosis of GSS and excluded other entities. We opted for prednisone treatment with an immunosuppressive dose, and started hematology follow-up. Currently, the patient is in clinical regression without manifestations of other lymphoproliferative diseases.

\section{Received on 02.09.2015.}

Approved by the Advisory Board and accepted for publication on 10.03.2016.

Work performed at Instituto Lauro de Souza Lima (ILSL) - Bauru (SP), Brazil.

Financial support: none.

Conflict of interest: none.

General Outpatient Dermatology Clinic at Instituto Lauro de Souza Lima (ILSL) - Bauru (SP), Brazil

Pathology Service at Instituto Lauro de Souza Lima (ILSL) - Bauru (SP), Brazil.

(C)2017 by Anais Brasileiros de Dermatologia 


\section{DISCUSSION}

GSS is an indolent subtype of MF and more frequently affects men between 14 and 69 years of age. ${ }^{1,2}$ It is characterized by erythematous-violet plaques, sometimes atrophic, that become pedunculated over the course of years. ${ }^{2,3}$ Although epidermotropism is rare and less intense than in classical MF, there are reports of characteristic epidermotropism and even of Pautrier's microabscess formation. Another histological feature that differs GSS from MF is
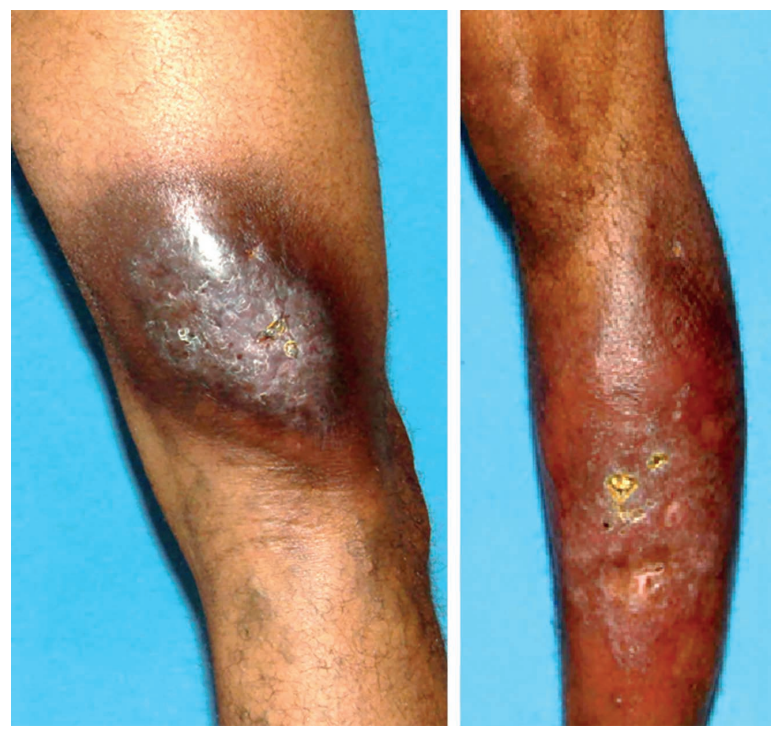

Figure 1: Hardened erythematous-violet plaques on the posterior aspect of the right thigh and anterior aspect of the left leg the dense infiltrate of small, atypical lymphocytes permeating the whole dermis and subcutaneous tissue, associated with multinucleated giant cells (containing 20 to 30 nuclei distributed near the periphery of the cell), elastophagocitosis, absence of elastic fibers in the lymphocytic infiltrate, and emperipolesis (characterized by the presence of lymphocytes in the cytoplasm of the multinucleated giant cells). The main histological differences between GMF and GSS include usually denser infiltrate with subcutaneous cellular tissue involvement and more lymphophagocytosis in GSS. Also, the loss of elastic fibers, which is focal in GMF, is intense in GSS. Despite these peculiarities, GMF may show histological overlap with GSS, which is its main differential diagnosis. The primary distinction between the two entities is established by clinical evolution and prognosis. ${ }^{4,9}$ GMF prognosis is restricted, with an overall 5-year survival rate of

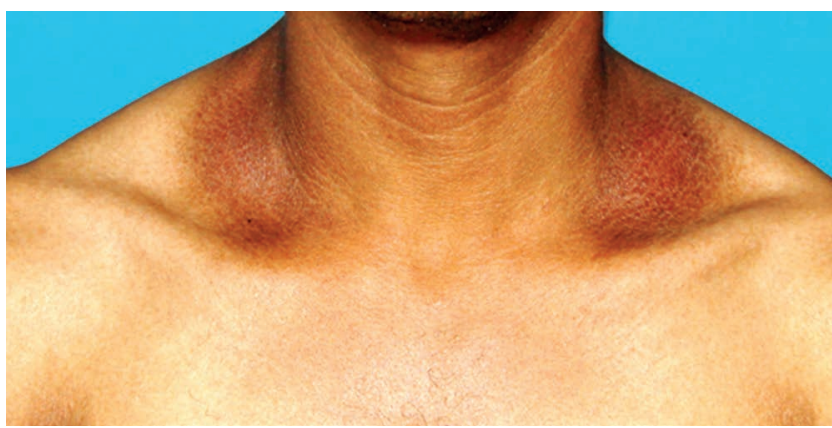

Figure 2: Atrophic and hyperchromic lesions with poorly defined margins in the bilateral supraclavicular region
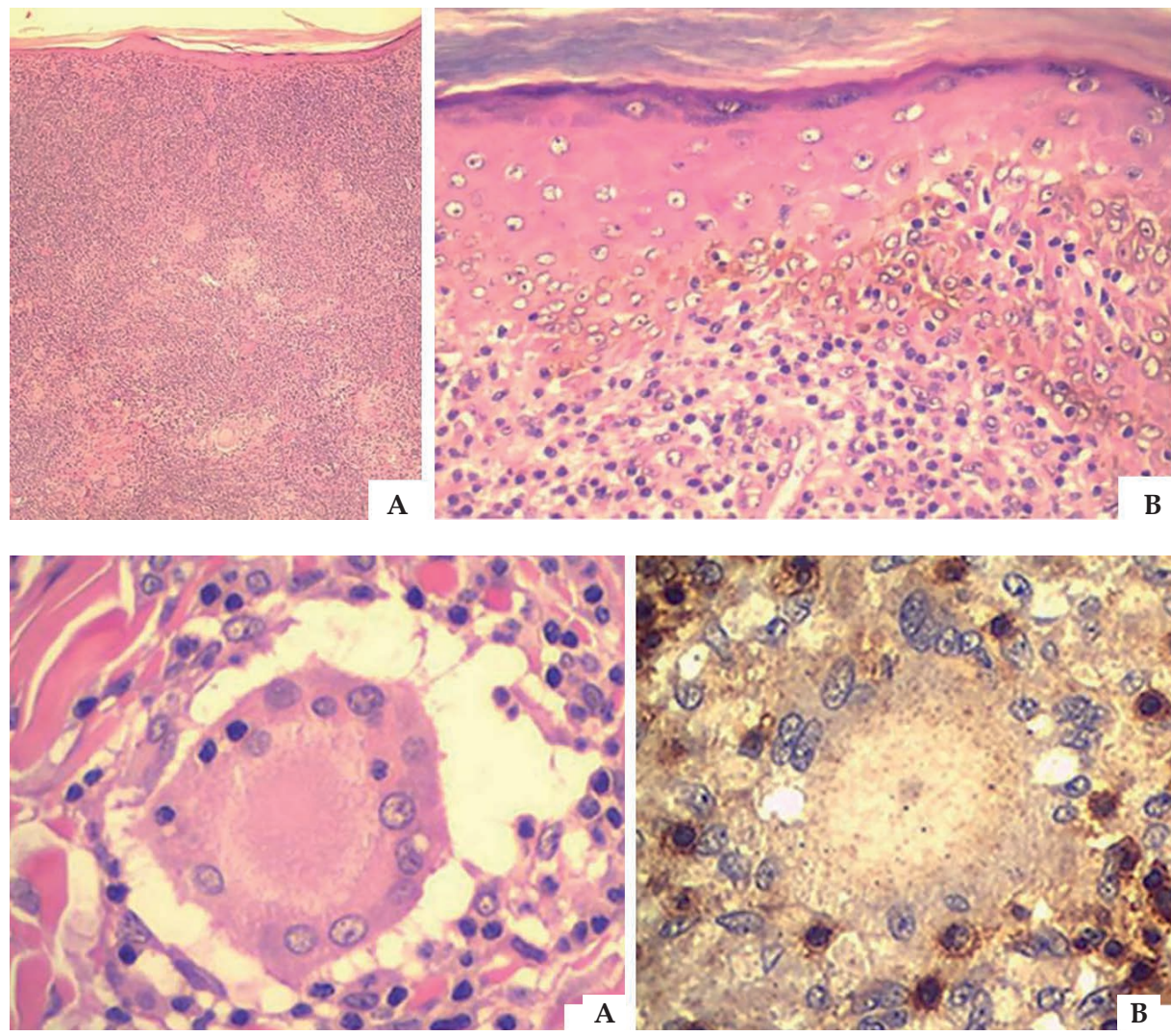

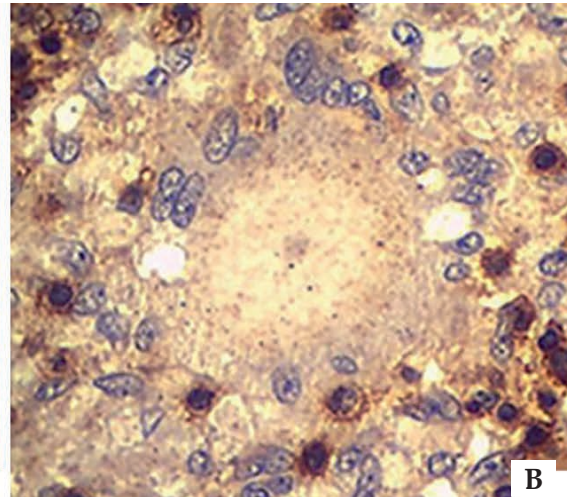

Figure 3:

(A) Deep and superficial atypical lymphocytic infiltrate accompanied by multinucleated giant cells with sketch of granulomas (Hematoxylin \& eosin, X40).

(B) Detail showing small and atypical lymphocytes with epidermotropism (Hematoxylin \& eosin, X200). Histological sample of the left leg

FIGURE 4:

(A) Emperipolese: multinucleated giant cells containing atypical lymphocytes (Hematoxylin \& eosin, X400). (B) Immunohistochemistry demonstrating CD4-positivite $\mathrm{T}$ lymphocytes in and adjacent to multinucleated giant cells (IHQ, X400) 

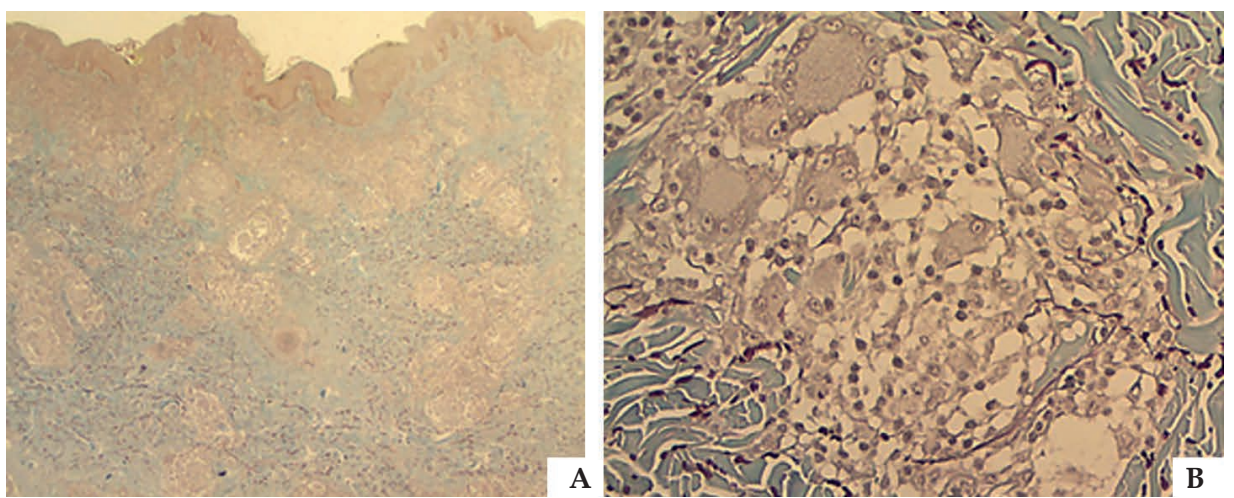

Figure 5:

(A) Elastic fibers bypassing the granulomatous reactions (Verhoeff, X20). (B) Absence of elastic fibers within the lymphocytic infiltrate (Verhoeff, X200)
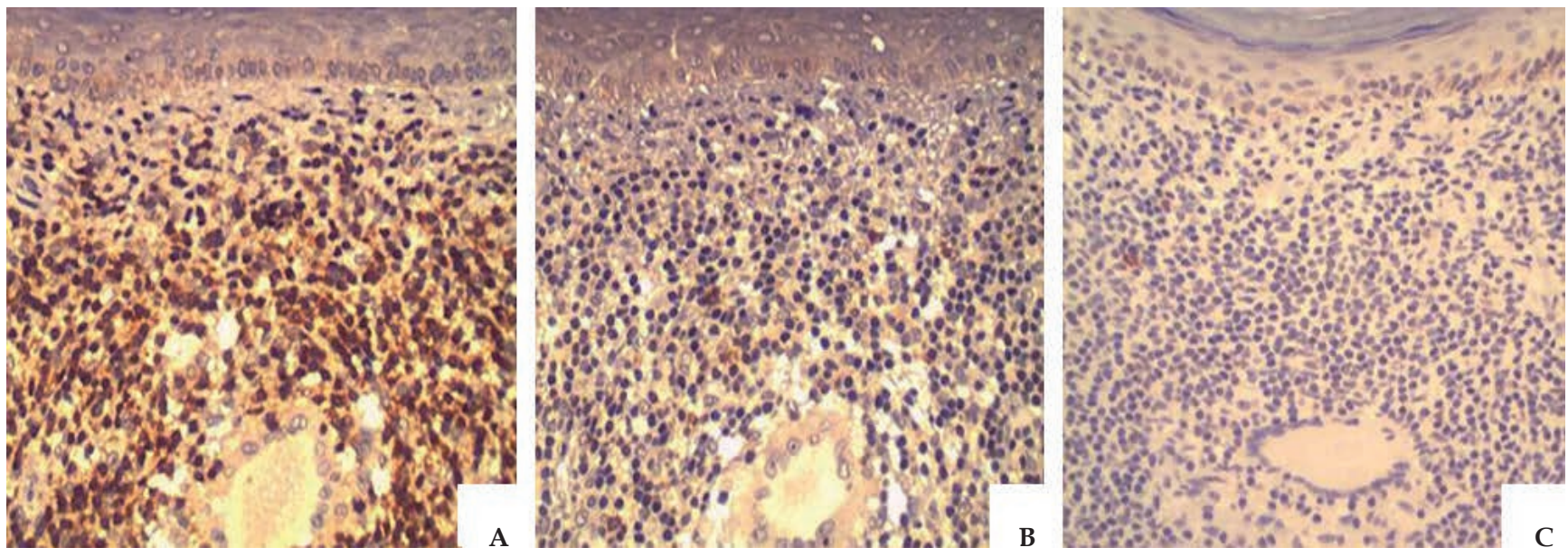

FIGURE 6: Immunohistochemistry evidencing a predominance of CD4-positive standard lymphocytes (A) and scanty pattern of CD8+ (B) and CD20+ (C) lymphocytes (Hematoxylin \& eosin, X200) Histological sample of the lesion on the left leg

$66 \%$, unlike GSS, which is indolent. ${ }^{7,8}$ Other differential diagnoses include: anetodermia, which are smaller and circumscribed lesions; generalized elastolysis (cutis laxa), which covers the face and other organs with absent granulomatous infiltration; and other granulomatous diseases, such as granuloma annulare and sarcoidosis, both without the dense atypical lymphocytic infiltrate. ${ }^{2}$ The immunohistochemical profile is similar to MF (atypical lymphocytes, T-helper, CD3+, CD4+, CD8-, and CD20- lymphocytes)..$^{1,2,4,6,7}$ In the present case, we reached the diagnosis of GSS due to the indolent behavior of the lesions, patient's good condition after long evolution, absence of systemic involvement, and histopathological results. The presence of emperipolesis in GSS may induce misdiagnosis of Rosai-Dorfman disease, as in our case. Several therapies are suggested, which include topical to systemic corticosteroids, surgical excision, nitrogen mustard, PUVA therapy, azathioprine, radiotherapy, and chemotherapy. ${ }^{2,45}$ It should be emphasized that, although indolent, GSS may be associated with other lymphoproliferative diseases, especially mycosis fungoides, Hodgkin's and non-Hodgkin's lymphomas, and Langerhans cell histiocytosis. ${ }^{3,4,5,8}$ Due to the risk of these diseases, constant monitoring is necessary in order to avoid unfavorable outcomes and increased morbidity and mortality. $\square$ 


\section{REFERENCES}

1. Burg G, Kempf W, Cozzio A, Feit J, Willemze R, S Jaffe E, et al. WHO/EORTC classification of cutaneous lymphomas 2005: histological and molecular aspects J Cutan Pathol. 2005:32:647-74.

2. van Haselen CW, Toonstra J, van der Putte SJ, van Dongen JJ, van Hees CL, van Vloten WA. Granulomatous Slack Skin: report of three patients with an updated review of the literature. Dermatology. 1998;196:382-91.

3. Balus L, Bassetti F, Gentili G. Granulomatous Slack Skin. Arch Dermatol. 1985;121:250-2

4. Goldsztajn KO, Moritz Trope B, Ribeiro Lenzi ME, Cuzzi T, Ramos-E-Silva M. Granulomatous slack skin. Histopathology diagnosis preceding clinical manifestations by 12 years. J Dermatol Case Rep. 2012;6:108-12

5. Hsiao PF, Hsiao CH, Tsai TF, Yao M, Jee SH. Granulomatous Slack Skin Presenting as Acquired Ichthyosis and Muscle Masses. Am J Clin Dermatol. 2009;10:29-32.

6. Ackerman AB. Granulomatous slack skin. In: Ackerman AB. Histologic Diagnosis of Inflammatory Skin Diseases. Philadelphia: Lea e Febiger; 1978. p.483-5.

7. Goodland J, Calonje E. Cutaneous Limphoproliferative diseases and related disorders. In: Calonje E, Brenn T, Lazar A, McKee PH. McKee's Pathology of the Skin. 4. ed. Philadelphia: Saunders; 2012. p. 1329-30 e 1337-38.

8. Sheng Y, Chen L, Huang Z, Mu Z, Kong J, Luo Y, et al. Granulomatous Slack Skin: Assesment of Disease Progression and Treatment Response Using Positron Emission Tomography/Computed Tomography. Clin Lymphoma Myeloma. 2009;9:455-8.

9. Kempf W, Ostheeren-Michaelis S, Paulli M, Lucioni M, Wechsler J, Audring H, et al. Granulomatous Mycosis Fungoides and Granulomatous Slack Skin: A Multicenter Study of the Cutaneous Lymphoma Histopathology Task Force Group of the European Organization for Research and Treatment of Cancer (EORTC). Arch Dermatol. 2008;144:1609-17.
MAILING ADDRESS:

Letícia Marra da Motta

SQN 402 bloco T - Apto. 208

Asa Norte

70834-200 Brasília, DF - Brazil

E-mail:draleticiamotta@gmail.com

How to cite this article: Motta LM, Soares CT, Nakandakari S, Silva GV, Nigro MH, Brandão LG. Granulomatous slack skin: a rare subtype of mycosis fungoides.. An Bras Dermtatol. 2017;92(5):694-7. 